Brit. J. industr. Med., 1965, 22, 157.

\title{
ASTHMA CAUSED BY THE GRAIN WEEVIL
}

\author{
BY \\ A. W. FRANKLAND and J. A. LUNN \\ From the Wright-Fleming Institute of Microbiology, St. Mary's Hospital, London, W.2 \\ and Slough Industrial Health Service, Farnham Road, Slough
}

(RECEIVED FOR PUBLICATION JUNE 13, 1964)

\begin{abstract}
The grain weevil (Sitophilus granarius) caused symptoms of allergic rhinitis and asthma in two laboratory workers, one after exposure to weevil dust for only six months and the other after three years. The former worker also noticed sneezing when she was cooking with National Flour. Skin testing with extracts of the grain weevil faecal dust gave positive skin responses. The antibodies were successfully transferred by passive sensitization using the Prausnitz-Kustner technique.

One hundred patients attending an allergy clinic for seasonal hay fever symptoms were also tested. All reacted to skin testing to a high dilution of grass pollens, and 51 gave some response to extracts of Sitophilus granarius; in 18 the wheal size was at least $6 \mathrm{~mm}$. in diameter. The significance of the positive responses in these 18 patients is at present unexplained.

One of the laboratory workers was so sensitive to weevil dust that she had to leave the laboratory; the other worker, by using an extractor fan and wearing a mask, could remain free of symptoms. Sitophilus granarius, like other insects, easily gives rise to inhalant allergic symptoms and may be a possible cause of baker's asthma which has not been previously considered.
\end{abstract}

All insects are strong sensitizers. Some of the ways in which insects cause different types of allergic reactions have recently been reviewed (Frankland, 1964). Small particles from insects easily become airborne, so that fine hairs and insect scales and faeces, particularly when dry, are potential inhalant allergens. Household dust contains dried insect faeces, but in a laboratory, which is breeding insects in large numbers, dry faecal débris tends to contaminate the air when the insects are being handled. It was previously pointed out (Frankland, 1953) that cleaning the cages in which locusts are bred distributed a cloud of fine locust faecal dust. This faecal dust caused a high incidence of rhinitis and asthma in laboratory workers who were allergy-prone, workers who generically had a family history of the atopic diseases or who themselves had already some allergic complaint. Wittich (1940) postulated that asthma due to mill dust could be due to the grain becoming contaminated by insects, and he was the first to describe allergic rhinitis and asthma due to the Mexican bean weevil (Zabrotes subfasciatus Boh) in bean sorters.

The present account concerns two laboratory workers who developed inhalant allergic symptoms from the dust of grain infested by Sitophilus granarius. The grain weevil (Sitophilus granarius (L) ) is a member of the family of beetles known as Curculionidae or true weevils. They have an elongated snout on the front of the head, at the tip of which are the mouth parts (Figure). Grain weevils attack all kinds of whole grain. The life history of grain weevils and the methods used to deal with infested grain are described in the Ministry of Agriculture, Fisheries and Food (1962) Advisory Leaflet 219. Besides the grain weevil, there are two almost indistinguishable other species of weevil which are important pests of grain, the rice weevil (Sitophilus oryzae (L)) and the maize weevil (Sitophilus zeamais Motschulsky). These weevils can fly in hot weather. They are very prolific but are not well adapted to the British climate.

\section{Methods}

Two different types of skin testing extracts were made. The technique used was that described by Coca (1922) using a weight/volume method. The ground up dead weevils (killed by chloroform), or the fine grey grain dust from a heavily contaminated colony bred in a large jar, were separated from the grain by sieving. Extracts of this dust and the 


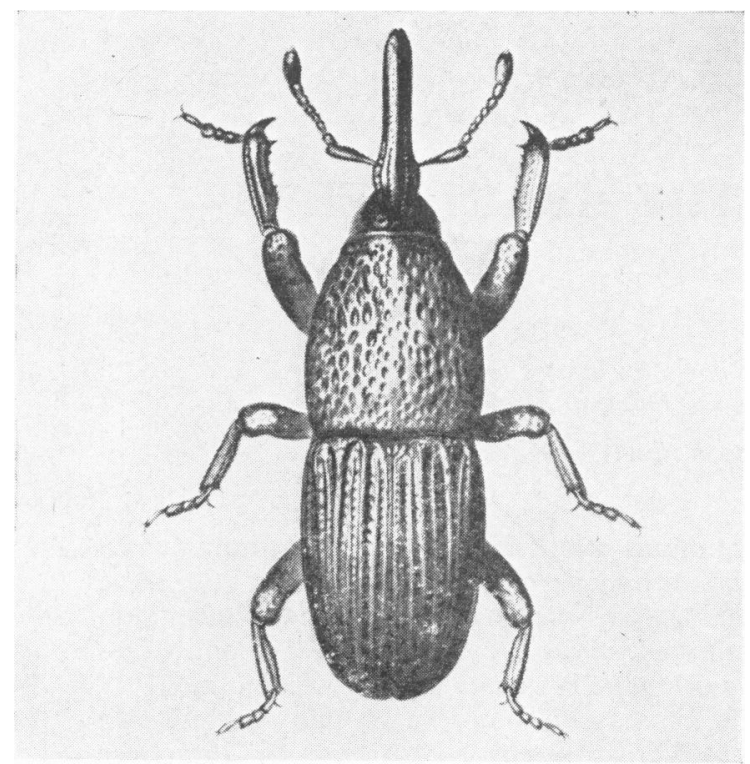

FIGURE.-Grain weevil (Sitophilus granarius). Actual length $3 \mathrm{~mm}$.

weevils gave similar sized wheals in sensitive patients. Microscopically it was noted that the weevil dust was heavily contaminated with penicillium species. This seemed to be the main contaminant obtained in the laboratory when the air was sampled by means of a rotor rod (Perkins, 1957). This air sampler consists essentially of a flat-faced rod carrying a sticky surface of a treated cellulose strip which can be removed, and any impacted particles are examined under a microscope. The rod spins at a rate of 2,500 revolutions per minute so that the number of particles per unit volume of air can be calculated.

\section{Illustrative Cases}

Case 1.-R.K. was a girl aged 19 years. She had no family history of any allergic complaint. When she was a child, cow's milk had caused abdominal pain. She still dislikes milk but it is difficult to say whether she is in any way allergic to it. She had worked in a laboratory with Sitophilus granarius for six months before she developed symptoms of sneezing, conjunctivitis, and urticaria on the neck. Two months later she developed a cough and became wheezy, and eventually asthma was diagnosed. She found that so long as she kept away from her work with the insects she was symptom free, except that when using National Flour in cooking at home she sneezed and her eyes became red and itchy. These symptoms from flour had not been noticed previously. She was skin tested using the prick method (Lewis and Grant, 1924). She gave positive responses to extracts of two grain dusts obtained from a sample of grain experimentally infected with Sitophilus granarius. The skin responses were measured at 15 minutes when they were maximal. The wheals obtained were $5 \mathrm{~mm}$. in diameter with a surrounding red flare. Positive skin responses were also obtained to Sitophilus oryzae and S. zeamais. The wheals obtained had a diameter of 9 and $6 \mathrm{~mm}$. respectively. She also gave a small positive skin response with a wheal of $3 \mathrm{~mm}$. in diameter to an extract of National Flour. All other skin tests to wheat, milk, pollens of the grasses, trees and weeds, to animal scurfs and fungal spores, including penicillium species, were negative. Passive transfer of the patient's reaginic antibodies using Sitophilus granarius as the allergen was successfully carried out using a modification of the Prausnitz-Kustner (1921) technique described by Chan (1963).

The patient was advised to move away from her work in the insect laboratory and she has had no further asthma. However, if she visits the laboratory, symptoms of rhinitis and conjunctivitis return after about 15 minutes. Any cooking at home, using flour, causes her to sneeze. It seems probable that in this patient it is the weevil infection of the flour that causes the symptoms. How often flour may be contaminated with weevil dust is at present under investigation.

Case 2.-B.D.H., a woman aged 38 , had worked since 1948 in a laboratory with Sitophilus granarius. On occasions she had worked with the rice but not the maize weevil. After about three years in the laboratory she noticed that symptoms of rhinitis occurred during work. The symptoms slowly became worse during the next 12 years and during the last three years a slight cough and wheeze had developed during working days. She, too, gave positive skin tests to the three grain weevil extracts. This patient clinically took very much longer to become sensitized to weevils than case 1 . She is able to work with them in the laboratory but is scrupulously careful to make sure that fine weevil dust does not become airborne. She always works with an extractor fan on and she wears a mask when working with dusty infected grain. Using these precautions and knowing that weevil dust is an allergen, she is able to continue working in the laboratory and remain free of symptoms which, until she was investigated, were becoming increasingly troublesome.

\section{Comparative Survey}

Since some insect skin testing extracts may contain histamine or related substances and since the two patients who had symptoms from the grain weevil gave markedly positive skin tests, it was decided to test other patients with the grain weevil extract. The most likely patients to give positive skin responses would be patients who, although having no known contact with weevil dust, were attending an allergy clinic for seasonal hay fever symptoms. One hundred of these patients, who all reacted on skin testing to a high dilution of the grass pollens, were tested against extracts of Sitophilus granarius and their faecal dust from contaminated wheat. 
Forty-nine gave negative skin tests to the weevil extracts. Fifty-one patients gave responses with a wheal size of more than $1 \mathrm{~mm}$. diameter. Most of the responses might be termed a doubtful positive, but in 18 patients the wheal size was $6 \mathrm{~mm}$. or more in diameter. The exact significance of definite positive responses in $18 \%$ of other allergic patients remains at present unexplained.

\section{Discussion}

The pattern of development of inhalant symptoms from insect emanations was quite typical in the two laboratory workers. However, the first patient noted that ordinary cooking flour had recently begun to cause rhinitis and conjunctivitis. Baker's asthma is a well-known hazard of the industry. It is noteworthy that quite often when skin testing patients with baker's asthma with stock extracts of flour or the individual components of flour, no positive skin response is obtained. When the patient's own flour is used, a marked positive response is obtained. Bonnevie (1958), writing on occupational allergy in the bakery professions, makes no mention of a possible insect aetiology. He does, however, mention that, besides the individual cereals used in flour, bakers are exposed to many fungi including aspergillus and penicillium. Pulmonary aspergillosis has been observed by one of the authors (A.W.F.) in a patient who had baker's asthma and who had a high contamination with Aspergillus fumigatus in the bakehouse. Efforts are always made to limit the infection of grain by weevils, but it seems to us that weevil faecal dust must be considered a cause of inhalant allergic disease, especially in laboratory workers using the insects and also in some cases of grain handler's and baker's asthma.

We are grateful to the Director, Agricultural Research Council, Pest Infestation Laboratory, Slough, for his co-operation and help.

\section{REFERENCES}

\footnotetext{
Bonnevie, P. (1958). In Occupational Allergy (European Academy of Allergy), p. 161. Stenfert Kroese, Leiden.

Chan, P. C. Y.(1963). Thesis for Ph.D., London University.

Coca, A. F. (1922). J. Immunol., 7, 163.

Frankland, A. W. (1953). Ann. Allergy, 11, 445.

Frankland, A. W. (1953). Ann. Allergy, 11,

Lewis, T., and Grant. R. T. (1924). Heart, 11, 209.

Lewis, T., and Grant, R. T. (1924). Heart, 11, 209. advisory leaflet 219 .

Perkins, W. A. (1957). Second Semi-annual Report, Aerosol Laboratory, Department Chemistry and Chemical Engng, Stanford University, Stanford, California.

Prausnitz, C., and Kustner, H. (1921). Zbl. Bakt., I. Abt. Orig., 86,

Wittich, F. W. (1940). J. Lancet, 60, 418.
}

\section{THE JANUARY (1965) ISSUE}

The January (1965) issue contains the following papers:-

Mortality of Gasworkers, with Special Reference to Cancers of the Lung and Bladder, Chronic Bronchitis and Pneumoconiosis. R. Doll, R. E. W. Fisher, E. J. Gammon, W. Gunn, G. O. Hughes, F. H. TYRER, and W. WILSON

A Study of the Concentrations of Polycyclic Aromatic Hydrocarbons in Gas Works Retort Houses. P. J. LAWTHER, B. T. Commins, and R. E. WALler

Urinary Excretion of Phenol by Men exposed to Vapour of Benzene: A Screening Test. S. G. RAINSFORD and T. A. Lloyd Davies

Byssinosis and Other Respiratory Symptoms in Flax Workers in Northern Ireland. P. C. Elwood, J. Pemberton, J. D. Merrett, G. C. R. Carey, and I. R. McAulay

Respiratory Symptoms in Men who had previously worked in a Flax Mill in Northern Ireland. P. C. Elwood

Delay in Restarting Respiration after Experimental Electric Shock. W. R. LeE, S. ZoledzIowsKI, and I. Dingwall FordyCE

Changes in the Prevalence of Coalworkers' Pneumoconiosis among Miners and Ex-miners in the Rhondda Fach 1951-61. A. L. Cochrane and J. ThOmas

Assessment of Mean Radiant Temperature in Indoor Environments. Barbara E. Tredre

Alterations in Serum Enzymes after Repeated Exposure to Malathion. J. L. GRECH

Mortality of Coal-miners from Carcinoma of the Lung. K. P. Goldman

Book Reviews

A number of copies are still available and may be obtained from the Publishing Manager, British Medical Association, Tavistock Square, W.C.1, price 18s. $6 d$. 